\title{
A Research Agenda for Microclimate Ecology in Human-Modified Tropical Forests
}

OPEN ACCESS

Edited by:

Sophie Fauset

University of Plymouth,

United Kingdom

Reviewed by:

Eleinis Ávila-Lovera,

University of California, Riverside,

United States

Scott Stark

Michigan State University,

United States

*Correspondence:

Tommaso Jucker

t.jucker@bristol.ac.uk

Specialty section:

This article was submitted to

Tropical Forests,

a section of the journal

Frontiers in Forests and Global

Change

Received: 19 September 2019

Accepted: 23 December 2019

Published: 17 January 2020

Citation:

Jucker T, Jackson TD, Zellweger F,

Swinfield T, Gregory N, Williamson J,

Slade EM, Phillips JW,

Bittencourt PRL, Blonder B,

Boyle MJW, Ellwood MDF,

Hemprich-Bennett D, Lewis OT,

Matula R, Senior RA, Shenkin A,

Svátek M and Coomes DA (2020) A

Research Agenda for Microclimate

Ecology in Human-Modified Tropical

Forests.

Front. For. Glob. Change 2:92.

doi: 10.3389/ffgc.2019.00092
Tommaso Jucker ${ }^{1 *}$, Tobias D. Jackson ${ }^{2}$, Florian Zellweger ${ }^{2,3}$, Tom Swinfield ${ }^{2}$, Nichar Gregory ${ }^{4}$, Joseph Williamson ${ }^{5}$, Eleanor M. Slade ${ }^{6}$, Josie W. Phillips ${ }^{7}$, Paulo R. L. Bittencourt ${ }^{8}$, Benjamin Blonder ${ }^{9,10}$, Michael J. W. Boyle ${ }^{4}$, M. D. Farnon Ellwood ${ }^{7}$, David Hemprich-Bennett ${ }^{11}$, Owen T. Lewis ${ }^{11}$, Radim Matula ${ }^{12}$, Rebecca A. Senior ${ }^{13}$, Alexander Shenkin ${ }^{10}$, Martin Svátek ${ }^{14}$ and David A. Coomes ${ }^{2}$

${ }^{1}$ School of Biological Sciences, University of Bristol, Bristol, United Kingdom, ${ }^{2}$ Forest Ecology and Conservation Group, Department of Plant Sciences, University of Cambridge, Cambridge, United Kingdom, ${ }^{3}$ Swiss Federal Institute for Forest, Snow and Landscape Research WSL, Birmensdorf, Switzerland, ${ }^{4}$ Department of Life Sciences, Imperial College London, Ascot, United Kingdom, ${ }^{5}$ School of Biological and Chemical Sciences, Queen Mary University of London, London, United Kingdom, ${ }^{6}$ Asian School of the Environment, Nanyang Technological University, Nanyang, Singapore, ${ }^{7}$ Centre for Research in Biosciences, University of the West of England, Bristol, United Kingdom, ${ }^{8}$ College of Life and Environmental Sciences, University of Exeter, Exeter, United Kingdom, ${ }^{9}$ School of Life Sciences, Arizona State University, Tempe, AZ, United States, ${ }^{10}$ Environmental Change Institute, School of Geography and the Environment, University of Oxford, Oxford, United Kingdom, ${ }^{11}$ Department of Zoology, University of Oxford, Oxford, United Kingdom, ${ }^{12}$ Department of Forest Ecology, Faculty of Forestry and Wood Sciences, Czech University of Life Sciences Prague, Prague, Czechia, ${ }^{13}$ Woodrow Wilson School of Public and International Affairs, Princeton University, Princeton, NJ, United States, ${ }^{14}$ Department of Forest Botany, Dendrology and Geobiocoenology, Faculty of Forestry and Wood Technology, Mendel University in Brno, Brno, Czechia

Logging and habitat fragmentation impact tropical forest ecosystems in numerous ways, perhaps the most striking of which is by altering the temperature, humidity, and light environment of the forest-its microclimate. Because local-scale microclimatic conditions directly influence the physiology, demography and behavior of most species, many of the impacts of land-use intensification on the biodiversity and ecosystem functioning of tropical forests have been attributed to changes in microclimate. However, the actual pathways through which altered microclimatic conditions reshape the ecology of these human-modified ecosystems remain largely unexplored. To bridge this knowledge gap, here we outline an agenda for future microclimate research in human-modified tropical ecosystems. We focus specifically on three main themes: the role of microclimate in shaping (i) species distributions, (ii) species interactions, and (iii) ecosystem functioning in tropical forests. In doing so we aim to highlight how a renewed focus on microclimate can help us not only better understand the ecology of human-modified tropical ecosystems, but also guide efforts to manage and protect them.

Keywords: ecosystem functioning, habitat loss and fragmentation, logging, microrefugia, remote sensing, species distribution modeling, species interactions, thermal corridors 


\section{INTRODUCTION}

More than half of the world's remaining tropical forests have been logged or otherwise impacted by human activities (Lewis et al., 2015). These human-modified tropical forests differ from their old-growth counterparts in a number of important ways (Ewers et al., 2015; Pfeifer et al., 2017; Riutta et al., 2018), as the impacts of logging and land clearing go well beyond the simple removal of biomass. For instance, logging often results in soil compaction and erosion (Putz et al., 2008), while the selective removal of tree species can directly alter the stoichiometry and function of the entire ecosystem (Riutta et al., 2018; Both et al., 2019; Swinfield et al., 2019). But perhaps the most pervasive impact of logging is that by opening and thinning the canopy, it increases solar radiation and air flow in the understorey and decreases evapotranspiration-thereby altering the forest's microclimate (Breshears, 2006; Hardwick et al., 2015; Senior et al., 2017). As a result, not only do logged forests tend to be warmer, drier and brighter than old-growth ones (Hardwick et al., 2015; Fauset et al., 2017; Senior et al., 2017), but microclimatic conditions in these human-modified ecosystems are also more spatially and temporally heterogeneous (Hardwick et al., 2015; Blonder et al., 2018).

These changes in microclimate have clear implications for the ecology of tropical forest ecosystems. Local-scale microclimatic conditions directly influence the physiology, demography, behavior and-ultimately-the distribution of a broad range of taxonomic groups in forests (Chen et al., 1999; Clarke, 2017). Because of this, many of the impacts of logging and habitat fragmentation on the biodiversity and ecosystem functioning of tropical forests have been attributed to changes in microclimate (Ewers et al., 2015). However, due to a lack of data in most cases this link between microclimate and ecosystem change has been assumed rather than directly observed. It is only with recent advances in environmental sensors and remote sensing that mapping microclimate at ecologically relevant scales has become a reality (Bramer et al., 2018; Jucker et al., 2018; Wild et al., 2019; Zellweger et al., 2019b; Figure 1). These new data streams provide an exciting opportunity to study the microclimate ecology of human-modified tropical forests.

Here, we explore the role of microclimate in regulating the ecology of human-modified tropical forests-from the lives of individual organisms to biogeochemical cycling at an ecosystem scale (Figure 2). Specifically, we outline how a microclimate-centered view can help us better understand the impacts of logging and habitat fragmentation on (i) the physiology, demography, behavior, and distribution of species; (ii) how species interact within and across taxonomic groups and trophic levels; and (iii) ecosystem functioning in human-modified tropical forests. In developing these ideas we primarily draw on examples from ongoing work at the Stability of Altered Forest Ecosystems (SAFE) project (Ewers et al., 2011) - a landscape-scale experiment designed to test how logging impacts the biodiversity and ecosystem functioning of Borneo's tropical forests. Our aim is to set an agenda for future research in the emerging field of microclimate ecology, with applications both in the tropics and beyond. We also explore how this new research field can inform efforts to better manage, conserve, and restore human-modified tropical landscapes.

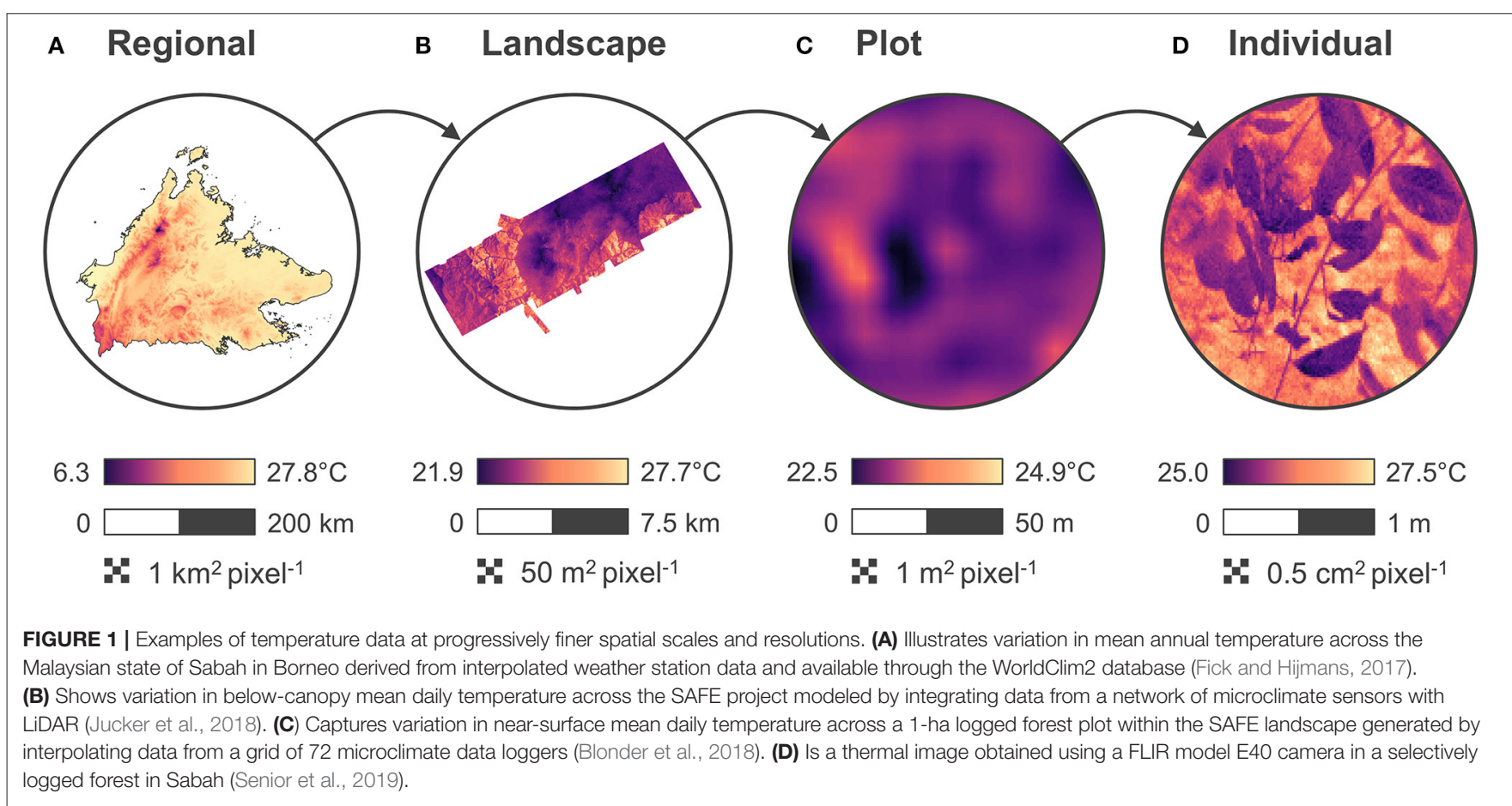




\section{Microclimate variation across human-modified tropical forests}
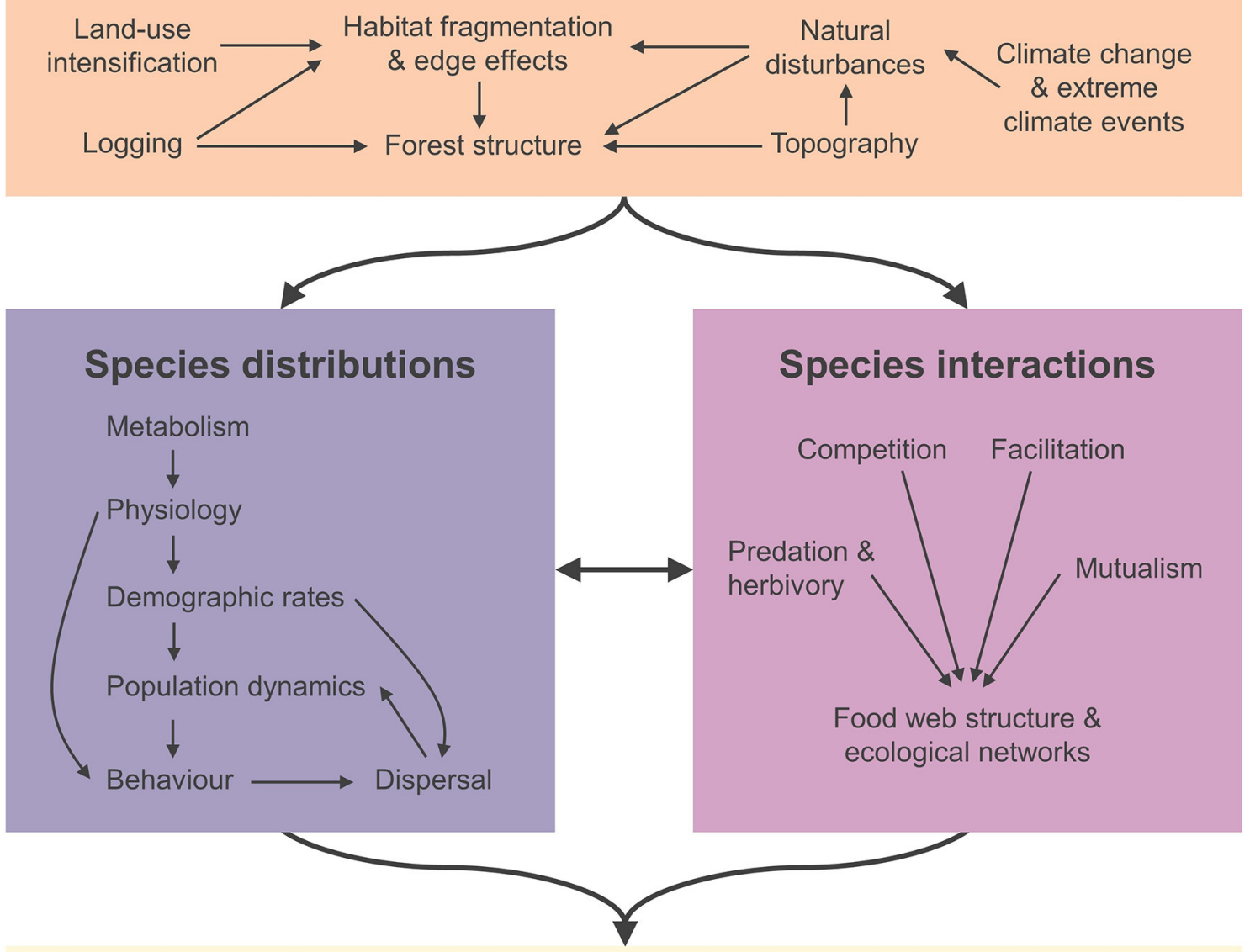

Ecosystem functions \& services

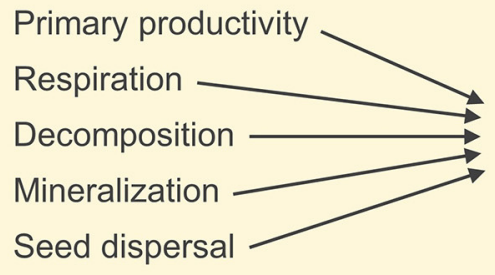

Nutrient cycling \& maintenance of biodiversity

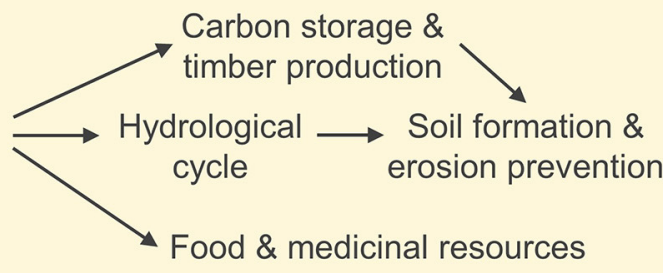

FIGURE 2 | Schematic diagram illustrating the key processes that drive variation in microclimate across human modified tropical forests, and how these in turn influence species distributions, their interactions and the ecosystem functions and services they underpin.

\section{SPECIES DISTRIBUTIONS AND POPULATION DYNAMICS}

A common assumption in species distribution modeling is that a lack of climate data at the "appropriate" spatial resolution limits our ability to make robust predictions about how species will respond to global change (Lenoir et al., 2017; Lembrechts et al., 2019b). This makes intuitive sense: in most cases the best climate data available are interpolated surfaces with a $1 \mathrm{~km}^{2}$ resolution that not only miss much of the finescale climate variability found within tropical landscapes, but are also unrepresentative of buffered habitats such as forests (Jucker et al., 2018; De Frenne et al., 2019). Yet only a handful of studies have actually compared the performance of models fit with microclimate and coarse-resolution climate data (Lembrechts et al., 2019a,b), nor is it clear what the 
"appropriate" spatio-temporal resolution of these microclimate data should be.

An initial priority is therefore to explore at what spatial scale microclimate data can prove most informative for distribution modeling (e.g., regional, landscape, plot, individual; Figure 1), and how this varies among species with contrasting life history traits (Potter et al., 2013; Scheffers et al., 2014). Similarly, we also need to tease apart which elements of microclimate are most important for predicting species distributions and develop clear guidelines and protocols for measuring them in standardized ways (Bramer et al., 2018). Given the role of temperature in regulating metabolism, as well as the fact that it can be measured accurately and cheaply, much emphasis has been placed on describing understorey air temperature heterogeneity in forests. But for some organisms microclimatic axes other than air temperature-such as surface temperature, humidity, vapor pressure deficit, soil moisture, solar radiation, or wind-may well prove more important in determining growth, reproduction and survival. Similarly, for many species microclimate extremes and temporal fluctuations-rather than mean values-may better predict their distribution (Mod et al., 2016). However, the challenge with teasing apart the relative importance of these various microclimatic axes is that temperature, relative humidity, soil moisture, and light levels will all tend to covary along disturbance gradients. Consequently, experimental setups that allow these different elements of microclimate to be manipulated independently are urgently needed (Cavaleri et al., 2015; De Frenne et al., 2015). These same experimental platforms would also provide a way to tease apart the effects of microclimate on species distributions from those of other drivers of environmental disturbance that are also associated with logging and habitat fragmentation.

Moving beyond purely correlational models, better microclimate data would also facilitate the development of population dynamics models that can provide a mechanistic framework for predicting species responses to forest degradation (Merow et al., 2014; Swab et al., 2015; Zurell et al., 2016). While this comes with the added challenge of having to build a detailed picture of how microclimate influences demography, there is growing interest in characterizing species' thermal nichesthe thermal boundaries within which individuals can persist and populations grow (GvoŽdík, 2018). Similarly, fine-scale microclimate data also provides an opportunity to determine species performances directly via energy budgets (Kearney and Porter, 2009). The SAFE project is an ideal testbed for this work, as physiological and behavioral responses to temperature have already been characterized for a number of functionally important invertebrate groups, including ants, termites, dung beetles, leeches and mosquitos (Drinkwater et al., 2019; Gregory et al., 2019; Woon et al., 2019; see Case study 1). Moreover, these data can be coupled with existing long-term microclimate records and high-resolution landscape maps of understorey temperature and vapor pressure deficit (Hardwick et al., 2015; Blonder et al., 2018; Jucker et al., 2018).

A key challenge is to identify which elements of an individual's microclimatic tolerance profile are most important for shaping population demography, as well as understanding if there are trade-offs in the way different vital rates (e.g., fecundity and mortality) are influenced by microclimate (Walsh et al., 2019). There is also a clear need to explore how and why thermal niches vary among species (e.g., ecto vs. endotherms; sessile vs. mobile; closely and distantly related phylogenetic and functional groups) (Dell et al., 2011), as well as within them (e.g., differences between life stages or sexes) (Bennett et al., 2019). Related to this, we need to understand what physiological and behavioral strategies species adopt to cope with or evade unfavorable microclimates. For instance, mobile species might shift from diurnal to nocturnal activity to escape warmer temperatures (Davison et al., 2019; Levy et al., 2019), while sessile organisms such as plants can thermoregulate by increasing transpiration and adjusting leaf angles (Fauset et al., 2017). Alternatively, some species may be able to rapidly acclimate and/or adapt to novel microclimates, as was recently shown for a poison frog in Costa Rica that exhibits higher preferred body temperatures in forests that have been logged (Rivera-Ordonez et al., 2019). Characterizing the traits that are favored by, or confer adaptability to, warmer microclimates may allow us to predict community responses to logging and forest fragmentation without relying on extensive species distribution data (Frishkoff et al., 2015; Bishop et al., 2016).

\section{Case Study 1: Impacts of Land-Use Intensification on Mosquitoes and Vector-Borne Diseases}

More than $80 \%$ of the human population is at risk of vectorborne disease (World Health Organisation., 2017). Climate is a key driver of disease dynamics, however the relationship between climate and disease transmission remains unclear (Kilpatrick and Randolph, 2012). Most models used to predict the effects of climate on transmission focus on temperature (Franklinos et al., 2019), using data collected at coarse spatio-temporal scales (Craig et al., 1999; Hoshen and Morse, 2004). As small-bodied ectotherms, insect vectors such as mosquitoes are instead more likely to respond to fine-scale temperature variations (Paaijmans et al., 2013; Beck-Johnson et al., 2017). Identifying what elements of microclimate shape insect vector life history is therefore critical to predicting population dynamics and developing vector control strategies. In field experiments spanning three years, Gregory et al. (2019) found that changes in temperature driven by tropical forest conversion to oil palm plantations dramatically altered larval development rates in the mosquito Aedes albopictus, which is the vector of dengue and chikungunya viruses (Figure 3). However, this response was mediated by the El Niño Southern Oscillation (ENSO) event of 2015-16. During non-ENSO years larval development rates were faster in oil palm plantations, where daytime temperatures were higher than those in logged forests. Increased temperatures during the ENSO event led to faster development rates in both land-use types. However, this increase was much more pronounced in logged forests, where development rates during the ENSO event were as fast as those observed in oil palm plantations. This suggests that in oil palm plantations, temperatures during the ENSO event may have exceeded the thermal development optimum of A. albopictus. 


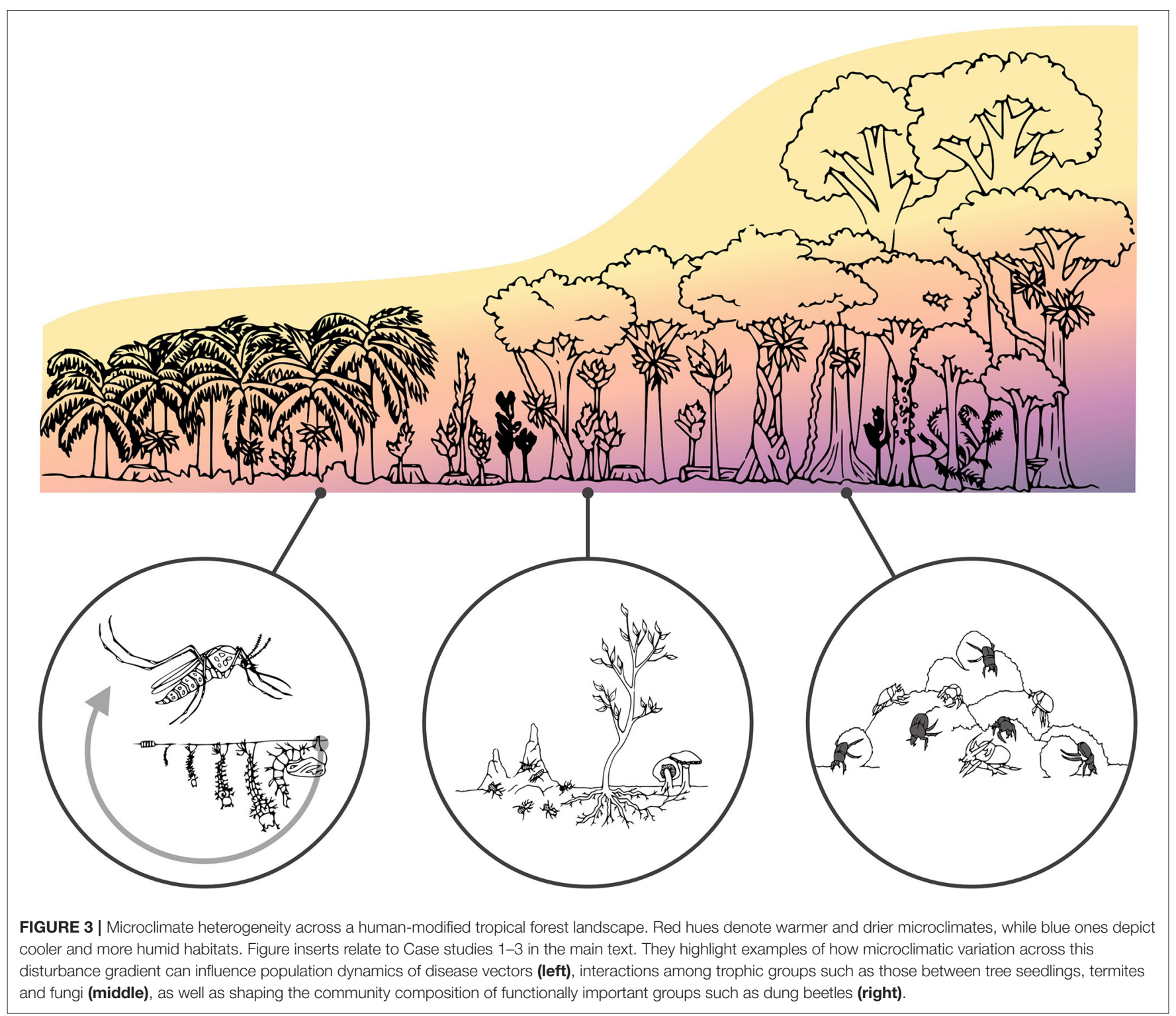

This work highlights how changes in climate and land-use can interact to shape vector demography and, ultimately, vectorborne disease incidence (MacDonald and Mordecai, 2019).

\section{SPECIES INTERACTIONS}

Because microclimate influences how species are distributed, their demographic rates and how they behave, it also plays an important role in structuring the complex network of interactions between species. These interactions, including competition, predation, herbivory, parasitism and mutualism, ultimately shape the biodiversity and functioning of ecosystems (Nakamura et al., 2017). So while some species may be able to tolerate a much greater range of microclimatic environments than others, these interactions mean that altered microclimate regimes of logged and degraded forests can impact them indirectly (Ewers et al., 2015; Kemp, 2018). The challenge with unpacking these direct and indirect effects of microclimate on species interactions is their sheer complexity, particularly when working in hyper-diverse tropical ecosystems (Novotny et al., 2010; Gripenberg et al., 2019). A review of how species interactions are affected by different global change drivers revealed substantial variation in the magnitude and direction of responses (Tylianakis et al., 2008). Because of this complexity, little progress has been made on understanding the cascading effects of microclimate heterogeneity and change across tropical food webs.

One way to address this knowledge gap is to reduce the complexity of the problem by leveraging natural microcosms or working with functionally important taxonomic groups (see Case study 2). Bird's nest ferns (Asplenium spp.) are a classic example of the former. By modifying their own microclimate 
through rainwater retention and evaporative cooling, these epiphytes can colonize and grow in a variety of environments, including old-growth forest understoreys, the high-canopy, logged forests, and even oil palm plantations. In doing so they support a large diversity and biomass of invertebrates that would not otherwise persist in these environments (Ellwood and Foster, 2004). The communities that inhabit these "islands in the sky" can be easily manipulated, making them excellent natural laboratories for studying how microclimate influences species interactions (Ellwood et al., 2009; Phillips et al., 2019). Using this model system, Phillips et al. (2019) revealed that by buffering ambient temperatures by several degrees, bird's nest ferns provide a key habitat for centipedes to build nests where their eggs are sheltered from daily fluctuations in air temperature and humidity that occur in the canopy. As a result, while adult centipedes show strong signs of spatial segregation and avoidance while foraging, a range of centipede species were found to share the same nest sites. So instead of competing for nests-as one might expect based on their typical behavior-centipedes are altering the way they interact with one another in order to access sites that are climatically suitable for egg-laying. Similarly, warming experiments conducted on artificially assembled communities have been used to explore how changes in competitive ability driven by microclimate impact dung beetle assemblages and the ecosystem functions they perform (Slade and Roslin, 2016). However, without incorporating the full breadth of antagonistic and synergistic processes that occur across trophic levels (e.g., Raine et al., 2018b), the outcomes of these experiments may not always reflect those observed in nature. It is therefore critical to pair manipulative experiments with larger-scale observational studies and models that together link pattern with process.

An alternative to working with simplified model systems is to explore how microclimate constrains entire ecological networks. While this is a relatively new field of research, there are some promising early results. For instance, Ohler et al. (2019) were able to identify a clear microclimate fingerprint in the spatial arrangement of alpine plant communities, which in turn shaped the composition and diversity of pollinators and their interactions with plants. Recent technological and computation advances (e.g., metabarcoding, acoustic monitoring, camera trapping, network analytics) are now opening the door to testing these same ideas in the tropics (Evans et al., 2016; Wearn et al., 2017; Burivalova et al., 2018). The development of new and ever-cheaper DNA sequencing approaches has enabled increasingly complex food webs to be resolved in detail (Creedy et al., 2019; Gripenberg et al., 2019). Others, instead, have used filming to reconstruct ant interaction networks and understand how they are impacted by forest disturbance, a proxy for microclimate (Gray et al., 2018). We can use these wellresolved interaction networks to explore how vulnerable they are to the loss of certain species, including ones that are most sensitive to changes in microclimate (Schleuning et al., 2016). This could be done in conjunction with existing and emerging climate manipulation experiments in the tropics (Cavaleri et al., 2015), which would provide a more robust platform for teasing apart microclimatic effects on species interactions from those of other drivers of global change associated with logging. By doing so we could begin building a clearer picture of how microclimatic constraints on species distributions, physiology, demography, and behavior come together to shape the biodiversity and ecosystem functioning of human-modified tropical forests.

\section{Case Study 2: of Tree Seedling, Termites, Fungi, and Drought}

Understanding the processes that shape the survival and growth of tree seedlings is critical to forecasting the structure, composition, and function of tomorrow's forests. Microclimatic conditions related to solar radiation, air temperature, vapor pressure deficit, and soil moisture all play a direct role in modulating plant ecophysiology and metabolism (Ashton and Gunatilleke, 1995; Will et al., 2013). But they can also affect seedling survival and growth indirectly, by altering competitive, facilitative, and mutualistic interactions with other species (Figure 3). For instance, mycorrhizal fungi can promote seedling growth and survival by increasing access to soil nutrients and moisture, and by conferring resistance to pests and pathogens (Brunner et al., 2015; Corrales et al., 2018). These fungal communities are themselves shaped by their surrounding microclimate. In Borneo, lowland forests are dominated by dipterocarps which, unlike most other tropical tree lineages, form associations exclusively with ectomycorrhizal fungi (Brearley, 2012). While these fungi have been shown to increase soil water uptake in inoculated seedlings (Brearley, 2011), there is evidence suggesting that they are susceptible to high soil temperatures (Smits, 1994), meaning they could be much less prevalent in warmer logged and degraded forests. Similarly, recent work by Ashton et al. (2019) showed that termites can alleviate the effects of drought on seedlings, as they increase soil moisture by transporting water upwards through the soil profile. However, termites are among the taxonomic groups worst affected by logging (Ewers et al., 2015; Tuma et al., 2019), with strong declines in diversity and abundance thought to be driven by the warmer and drier microclimate of degraded forests (Jucker et al., 2018). As a result, seedlings in logged forests could lose two key allies in their search for water: ectomycorrhizal fungi and termites. This may have contributed to their lower survival during the 2015-16 El Niño drought compared to their counterparts in Borneo's oldgrowth forests (Qie et al., 2019). Further work is needed to test this hypothesis, but the implications for forest regeneration could be substantial. In particular, there is a risk that if seedlings in degraded secondary forests struggle to recruit due to unfavorable microclimatic conditions, heavily logged forests could find themselves in a state of arrested succession from which recovery is much slower (Jucker et al., 2018). This microclimate "trap" is likely to be further exacerbated by climate change and would lead to an increased risk of fire, which in turn could set in motion a positive feedback loop that pushes these ecosystems toward a more open, savanna-like state (Silvério et al., 2013). 


\section{ECOSYSTEM FUNCTIONING}

Through its influence on all aspects of organismal biology and on the structure and composition of ecological communities, microclimate inevitably also plays a role in shaping a range of ecosystem-level processes. These include processes associated with nutrient cycling, such as net primary productivity, decomposition, respiration, and nutrient mineralization. However, we lack a quantitative understanding of how important microclimate is in regulating these processes relative to other factors such as soils, canopy structure, and disturbance history (Bradford et al., 2014; Keiser and Bradford, 2017; Chen et al., 2018; Pau et al., 2018). Nor do we know to what degree microclimatic influences on ecosystem functioning are direct (e.g., constraining net carbon assimilation rates by plants, determining canopy transpiration rates, regulating activity of decomposers) or indirect (e.g., shaping community composition and interaction networks). Addressing these uncertainties would allow the development of more realistic ecosystem models of human-modified tropical forests and a better understanding of the likely impacts of global change on these systems.

Manipulative experiments that alter microclimatic conditions while controlling for other potentially confounding effects provide one way forward. Microclimate can be manipulated either actively (e.g., rainfall exclusion, heating, shading; Cavaleri et al., 2015) or passively (e.g., through transplant experiments across microclimate gradients associated with canopy cover or microtopography; Jucker et al., 2018). Taking wood decomposition and soil faunal activity as an example, experiments such as these can be used to identify the primary microclimatic controls of wood decay (Crockatt and Bebber, 2015), compare these effects to those of other local-scale drivers (Bradford et al., 2014) and understand how they are mediated by changes in the decomposer community and by wood traits (Weedon et al., 2009; Riutta et al., 2016; Cheesman et al., 2018). The challenge with these experimental approaches is balancing realism and scale with costs.

An alternative approach to scaling-up the effects of microclimate on ecosystem functioning is to combine distribution, abundance, and functional trait data of functionally important taxonomic groups with regional microclimate maps and measures of ecosystem functioning (see Case study 3). Along with dung beetles, termites would be a good candidate group for this work, as they contribute disproportionately to decomposition and soil bioturbation in tropical forests (Griffiths et al., 2019; Tuma et al., 2019) and appear to be strongly susceptible to changes in microclimate that result from logging (Ewers et al., 2015). This approach could be used to test the extent to which changes in community composition and diversity driven by microclimate impact ecosystem functioning (Slade et al., 2019; Tuma et al., 2019). The challenge, however, lies in the inherent complexity of scaling species abundances and interactions, particularly when working in data-poor regions. What remains unclear is whether we even need to account for this level of complexity, or if instead we could simply measure and model broad scale patterns in ecosystem functioning directly. High spatial and spectral resolution remote sensing imagery would be one way to up-scale data from localized experiments. Using litter decomposition as an example, key components of this process could be estimated accurately using airborne LiDAR and hyperspectral imagery (Krishna and Mohan, 2017), including microclimate (Jucker et al., 2018), litter quantity (Detto et al., 2015), litter quality (Asner et al., 2015), and solar radiation (Zellweger et al., 2019a).

\section{Case Study 3: Dung Beetles and Nutrient Cycling in Human-Modified Tropical Forests}

Dung beetles are a widely used indicator group, as they play a key role in driving numerous ecosystems functions-such as nutrient cycling and seed dispersal-and can be easily sampled using pitfall traps (Nichols et al., 2008). Across the SAFE landscape dung beetle diversity, abundance and traits have been extensively surveyed, as has their contribution to nutrient cycling through dung removal (Raine et al., 2018a). By combining these data with existing high-resolution microclimate maps of understorey temperature and vapor pressure deficit (Jucker et al., 2018), dung beetle abundance and community composition can be extrapolated across the oil palm-forest mosaic landscape. In this way one can explore how changes in the diversity and trait composition of dung beetle communities associated with microclimate gradients impact soil nutrient cycling across human-modified tropical landscapes (Figure 3). This research would add to the growing body of literature exploring whether biodiversity loss driven by land-use change leads to a collapse in ecosystem functioning, or if instead relatively species-poor communities of disturbance-resistant species are able to maintain high levels of ecosystem functioning (Slade et al., 2017, 2019; Tuma et al., 2019). It would also allow us to model the likely impacts of different land-use change scenarios on biodiversity and ecosystem functioning in tropical landscapes where the aim is to balance conservation with economic development. These models would enable ecologists and conservation scientist to inform policy and management decisions, such as those related to the importance of riparian buffer zones in oil palm plantations as ecological and microclimatic corridors (Luke et al., 2019).

\section{GUIDING CONSERVATION AND RESTORATION EFFORTS IN HUMAN-MODIFIED TROPICAL FORESTS}

In addition to advancing our understanding of the ecology of human-modified tropical forests, a renewed focus on microclimate would also benefit efforts to better manage, conserve and restore these ecosystems. Mapping horizontal, vertical, and temporal variation in microclimate at landscape and regional scales (e.g., Jucker et al., 2018) would help identify dispersal corridors that are climatically suitable for a range of taxonomic groups (Milanesi et al., 2017). This would allow microclimate ecology to be integrated into classical landscape ecology and metacommunity dynamics (Hesselbarth et al., 2019; Senior et al., 2019), and also guide efforts to restore and increase connectivity in fragmented landscapes (e.g., through 
the rehabilitation of riparian buffer zones; Luke et al., 2019). It also provides an opportunity to assess the effectiveness of different forest and plantation management practices that aim to restore microclimate regimes by altering canopy structure and ecophysiology, such as natural regeneration, enrichment planting, and climber cutting (Rodríguez-Ronderos et al., 2016; Ichihashi et al., 2017; Guzmán et al., 2018). Moreover, this would also provide an opportunity to understand how different management interventions alter specific facets of microclimate (e.g., impact of liana cutting on transpiration) and whether these can be tailored to restore specific microclimatic conditions.

A further application would be to characterize the microclimate niche breadth of different forest and land-use types (i.e., the range of microclimatic conditions experienced within an area of interest) and map how this varies horizontally and vertically across entire landscapes (Scheffers et al., 2017; Blonder et al., 2018). This would facilitate identifying the distribution, abundance, and connectivity of microrefugia, which have been shown to play a critical role in enabling species to persist through extreme climate events (Scheffers et al., 2014). It would also provide a way to relate data from biodiversity surveys to microclimate and its heterogeneity. Such models would shed light on how microclimate contributes to structuring tropical forest biodiversity and would provide a tool to forecast the potential impacts of climate change and land-use intensification on these ecosystems. However, to realize the full potential of new microclimate data streams, we need to standardize how they are measured and pair them with sensors that capture the physiology, chemistry, growth, movement, interactions and genetics of organisms (e.g., camera traps, acoustic sensors, dendrometers, sap flow sensors, thermal imagery, eDNA readers; Porter et al., 2009). While the development of these biological sensors has lagged behind that of meteorological ones, the advent of low-cost, open-source hardware and software components is leveling the playing field (Pearce, 2012). Integrated biophysical

\section{REFERENCES}

Ashton, L. A., Griffiths, H. M., Parr, C. L., Evans, T. A., Didham, R. K., Hasan, F., et al. (2019). Termites mitigate the effects of drought in tropical rainforest. Science 363, 174-177. doi: 10.1126/science.aau9565

Ashton, P. M. S., and Gunatilleke, C. V. S. (1995). Seedling survival and growth of four Shorea species in a Sri Lankan rainforest. J. Trop. Ecol. 11, 263-279. doi: $10.1017 /$ S0266467400008737

Asner, G. P., Martin, R. E., Anderson, C. B., and Knapp, D. E. (2015). Quantifying forest canopy traits: imaging spectroscopy versus field survey. Remote Sens. Environ. 158, 15-27. doi: 10.1016/j.rse.2014.11.011

Beck-Johnson, L. M., Nelson, W. A., Paaijmans, K. P., Read, A. F., Thomas, M. B., and Bjørnstad, O. N. (2017). The importance of temperature fluctuations in understanding mosquito population dynamics and malaria risk. $R$. Soc. Open Sci. 4:160969. doi: 10.1098/rsos.160969

Bennett, S., Duarte, C. M., Marbà, N., and Wernberg, T. (2019). Integrating withinspecies variation in thermal physiology into climate change ecology. Philos. Trans. R. Soc. B Biol. Sci. 374:20180550. doi: 10.1098/rstb.2018.0550

Bishop, T. R., Robertson, M. P., Gibb, H., van Rensburg, B. J., Braschler, B., Chown, S. L., et al. (2016). Ant assemblages have darker and larger members in cold environments. Glob. Ecol. Biogeogr. 25, 1489-1499. doi: 10.1111/geb.12516

Blonder, B., Both, S., Coomes, D. A., Elias, D., Jucker, T., Kvasnica, J., et al. (2018). Extreme and highly heterogeneous microclimates in selectively sensor networks-coupled with advances in remote sensing and computing-promise to revolutionize our understanding of the microclimate ecology of human-modified tropical forests.

\section{AUTHOR CONTRIBUTIONS}

TJ and DC conceived the idea for the paper. TJ led the writing with help from TDJ, FZ, and TS. TJ, TDJ, NG, JW, and ES developed the case studies. JP produced the drawings for Figure 3. All authors contributed substantially to revisions and worked together to define the structure and content of the paper.

\section{FUNDING}

This study was funded by the UK Natural Environment Research Council's (NERC) Human Modified Tropical Forests Programme (Grant No. NE/K016377/1 and NE/K016407/1 awarded to the BALI and LOMBOK consortia, respectively). TJ was supported by a UK NERC Independent Research Fellowship (Grant No. NE/S01537X/1). FZ was funded by the Swiss National Science Foundation (Grant No. 172198) and the Isaac Newton Trust. PB was funded by a Royal Society Newton International Fellowship (Grant No. NF170370). MS was supported through a grant from the Ministry of Education, Youth and Sports of the Czech Republic (Grant No. LTT17017).

\section{ACKNOWLEDGMENTS}

This publication resulted from a workshop held during the Science at SAFE meeting at Imperial College London on the 27-29th March 2019. We are grateful to Robert Ewers and Olivia Daniel for organizing the Science at SAFE meeting. We also thank Yit Arn Teh, David Burslem, and Sabine Both for coordinating the special issue on Land-use Change Impacts on Tropical Ecosystems.

logged tropical forests. Front. For. Glob. Chang. 1:5. doi: 10.3389/ffgc.2018. 00005

Both, S., Riutta, T., Paine, C. E. T., Elias, D. M. O., Cruz, R. S., Jain, A., et al. (2019). Logging and soil nutrients independently explain plant trait expression in tropical forests. N. Phytol. 221, 1853-1865. doi: 10.1111/nph.15444

Bradford, M. A., Warren, R. J. I., Baldrian, P., Crowther, T. W., Maynard, D. S., Oldfield, E. E., et al. (2014). Climate fails to predict wood decomposition at regional scales. Nat. Clim. Chang. 4, 625-630. doi: 10.1038/nclimate2251

Bramer, I., Anderson, B. J., Bennie, J., Bladon, A. J., De Frenne, P., Hemming, D., et al. (2018). Advances in monitoring and modelling climate at ecologically relevant scales. Adv. Ecol. Res. 58, 101-161. doi: 10.1016/bs.aecr.2017. 12.005

Brearley, F. Q. (2011). "The importance of ectomycorrhizas for the growth of Dipterocarps and the efficacy of ectomycorrhizal inoculation schemes," in Diversity and Biotechnology of Ectomycorrhizae, eds M. Rai, and A. Varma (Berlin: Springer-Verlag), 3-17. doi: 10.1007/978-3-642-15196-5_1

Brearley, F. Q. (2012). Ectomycorrhizal associations of the Dipterocarpaceae. Biotropica 44, 637-648. doi: 10.1111/j.1744-7429.2012.00862.x

Breshears, D. D. (2006). The grassland-forest continuum: trends in ecosystem properties for woody plant mosaics? Front. Ecol. Environ. 4, 96-104. doi: 10. 1890/1540-9295(2006)004[0096:TGCTIE]2.0.CO;2

Brunner, I., Herzog, C., Dawes, M. A., Arend, M., and Sperisen, C. (2015). How tree roots respond to drought. Front. Plant Sci. 6:547. doi: 10.3389/fpls.2015.00547 
Burivalova, Z., Towsey, M., Boucher, T., Truskinger, A., Apelis, C., Roe, P., et al. (2018). Using soundscapes to detect variable degrees of human influence on tropical forests in Papua New Guinea. Conserv. Biol. 32, 205-215. doi: $10.1111 /$ cobi.12968

Cavaleri, M. A., Reed, S. C., Smith, W. K., and Wood, T. E. (2015). Urgent need for warming experiments in tropical forests. Glob. Chang. Biol. 21, 2111-2121. doi: $10.1111 /$ gcb. 12860

Cheesman, A. W., Cernusak, L. A., and Zanne, A. E. (2018). Relative roles of termites and saprotrophic microbes as drivers of wood decay: a wood block test. Austral Ecol. 43, 257-267. doi: 10.1111/aec.12561

Chen, J., Saunders, S. C., Crow, T. R., Naiman, R. J., Brosofske, K. D., Mroz, G. D., et al. (1999). Microclimate in forest ecosystem and landscape ecology. Bioscience 49, 288-297. doi: 10.2307/1313612

Chen, Y., Liu, Y., Zhang, J., Yang, W., He, R., and Deng, C. (2018). Microclimate exerts greater control over litter decomposition and enzyme activity than litter quality in an alpine forest-tundra ecotone. Sci. Rep. 8:14998. doi: 10.1038/s41598-018-33186-4

Clarke, A. (2017). Principles of Thermal Ecology: Temperature, Energy and Life. Oxford University Press. Available online at: https://global.oup.com/ academic/product/principles- of-thermal-ecology-temperature-energy-andlife- $9780199551668 ? \mathrm{cc}=$ au\&lang=en \& (accessed February 19, 2018).

Corrales, A., Henkel, T. W., and Smith, M. E. (2018). Ectomycorrhizal associations in the tropics--biogeography, diversity patterns and ecosystem roles. $N$. Phytol. 220, 1076-1091. doi: 10.1111/nph.15151

Craig, M. H., Snow, R. W., and le Sueur, D. (1999). A climate-based distribution model of malaria transmission in Sub-Saharan Africa. Parasitol. Today 15, 105-111. doi: 10.1016/S0169-4758(99)01396-4

Creedy, T. J., Ng, W. S., and Vogler, A. P. (2019). Toward accurate species-level metabarcoding of arthropod communities from the tropical forest canopy. Ecol. Evol. 9, 3105-3116. doi: 10.1002/ece3.4839

Crockatt, M. E., and Bebber, D. P. (2015). Edge effects on moisture reduce wood decomposition rate in a temperate forest. Glob. Chang. Biol. 21, 698-707. doi: $10.1111 /$ gcb.12676

Davison, C. W., Chapman, P. M., Wearn, O. R., Bernard, H., and Ewers, R. M. (2019). Shifts in the demographics and behavior of bearded pigs (Sus barbatus) across a land-use gradient. Biotropica 51, 938-948. doi: 10.1111/btp.12724

De Frenne, P., Rodríguez-Sánchez, F., De Schrijver, A., Coomes, D. A., Hermy, M., Vangansbeke, P., et al. (2015). Light accelerates plant responses to warming. Nat. Plants 1:15110. doi: 10.1038/nplants.2015.110

De Frenne, P., Zellweger, F., Rodríguez-Sánchez, F., Scheffers, B. R., Hylander, K., Luoto, M., et al. (2019). Global buffering of temperatures under forest canopies. Nat. Ecol. Evol. 3, 744-749. doi: 10.1038/s41559-019-0842-1

Dell, A. I., Pawar, S., and Savage, V. M. (2011). Systematic variation in the temperature dependence of physiological and ecological traits. Proc. Natl. Acad. Sci. U.S.A. 108, 10591-10596. doi: 10.1073/pnas. 1015178108

Detto, M., Asner, G. P., Muller-landau, H. C., and Sonnentag, O. (2015). Spatial variability in tropical forest leaf area density from multireturn LiDAR and modeling. J. Geophys. Res. Biogeosci. 2, 294-309. doi: 10.1002/2014JG002774

Drinkwater, R., Williamson, J., Swinfield, T., Deere, N. J., Struebig, M. J., Clare, E. L., et al. (2019). Occurrence of blood-feeding terrestrial leeches (Haemadipsidae) in a degraded forest ecosystem and their potential as ecological indicators. Biotropica. doi: 10.1111/btp.12686. [Epub ahead of print].

Ellwood, M. D. F., and Foster, W. A. (2004). Doubling the estimate of invertebrate biomass in a rainforest canopy. Nature 429, 549-551. doi: 10.1038/nature02560

Ellwood, M. D. F., Manica, A., and Foster, W. A. (2009). Stochastic and deterministic processes jointly structure tropical arthropod communities. Ecol. Lett. 12, 277-284. doi: 10.1111/j.1461-0248.2009.01284.x

Evans, D. M., Kitson, J. J. N., Lunt, D. H., Straw, N. A., and Pocock, M. J. O. (2016). Merging DNA metabarcoding and ecological network analysis to understand and build resilient terrestrial ecosystems. Funct. Ecol. 30, 1904-1916. doi: 10.1111/1365-2435.12659

Ewers, R. M., Boyle, M. J. W., Gleave, R. A., Plowman, N. S., Benedick, S., Bernard, H., et al. (2015). Logging cuts the functional importance of invertebrates in tropical rainforest. Nat. Commun. 6:6836. doi: 10.1038/ncomms7836

Ewers, R. M., Didham, R. K., Fahrig, L., Ferraz, G., Hector, A., Holt, R. D., et al. (2011). A large-scale forest fragmentation experiment: the stability of altered forest ecosystems project. Philos. Trans. R. Soc. B 366, 3292-3302. doi: 10.1098/rstb.2011.0049
Fauset, S., Gloor, M. U., Aidar, M. P. M., Freitas, H. C., Fyllas, N. M., Marabesi, M. A., et al. (2017). Tropical forest light regimes in a human-modified landscape. Ecosphere 8:e02002. doi: 10.1002/ecs2.2002

Fick, S. E., and Hijmans, R. J. (2017). WorldClim 2: new 1-km spatial resolution climate surfaces for global land areas. Int. J. Climatol. 37, 4302-4315. doi: $10.1002 /$ joc. 5086

Franklinos, L. H. V., Jones, K. E., Redding, D. W., and Abubakar, I. (2019). The effect of global change on mosquito-borne disease. Lancet Infect. Dis. 19:e302-e312. doi: 10.1016/S1473-3099(19)30161-6

Frishkoff, L. O., Hadly, E. A., and Daily, G. C. (2015). Thermal niche predicts tolerance to habitat conversion in tropical amphibians and reptiles. Glob. Change Biol. 21, 3901-3916. doi: 10.1111/gcb.13016

Gray, R. E. J., Ewers, R. M., Boyle, M. J. W., Chung, A. Y. C., and Gill, R. J. (2018). Effect of tropical forest disturbance on the competitive interactions within a diverse ant community. Sci. Rep. 8:5131. doi: 10.1038/s41598-018-2 $3272-y$

Gregory, N., Ewers, R. M., Chung, A. Y. C., and Cator, L. J. (2019). El niño drought and tropical forest conversion synergistically determine mosquito development rate. Environ. Res. Lett. 14:035003. doi: 10.1088/1748-9326/ab0036

Griffiths, H. M., Ashton, L. A., Evans, T. A., Parr, C. L., and Eggleton, P. (2019). Termites can decompose more than half of deadwood in tropical rainforest. Curr. Biol. 29, 118-119. doi: 10.1016/j.cub.2019.01.012

Gripenberg, S., Basset, Y., Lewis, O. T., Terry, J. C. D., Wright, S. J., Simón, I., et al. (2019). A highly resolved food web for insect seed predators in a species-rich tropical forest. Ecol. Lett. 22, 1638-1649. doi: 10.1111/ele.13359

Guzmán, A. J. Q., Sanchez-Azofeifa, G. A., and Rivard, B. (2018). Differences in leaf temperature between lianas and trees in the neotropical canopy. Forests 9 , 1-12. doi: 10.3390/f9060307

GvoŽdík, L. (2018). Just what is the thermal niche? Oikos 127, 1701-1710. doi: 10.1111/oik.05563

Hardwick, S. R., Toumi, R., Pfeifer, M., Turner, E. C., Nilus, R., and Ewers, R. M. (2015). The relationship between leaf area index and microclimate in tropical forest and oil palm plantation: forest disturbance drives changes in microclimate. Agric. For. Meteorol. 201, 187-195. doi: 10.1016/j.agrformet.2014.11.010

Hesselbarth, M. H. K., Sciaini, M., With, K. A., Wiegand, K., and Nowosad, J. (2019). Landscapemetrics : an open-source R tool to calculate landscape metrics. Ecography 42:04617. doi: 10.1111/ecog.04617

Hoshen, M. B., and Morse, A. P. (2004). A weather-driven model of malaria transmission. Malar. J. 3:32. doi: 10.1186/1475-2875-3-32

Ichihashi, R., Chiu, C.-W., Komatsu, H., Kume, T., Shinohara, Y., Tateishi, M., et al. (2017). Contribution of lianas to community-level canopy transpiration in a warm-temperate forest. Funct. Ecol. 31, 1690-1699. doi: 10.1111/1365-2435.12881

Jucker, T., Hardwick, S. R., Both, S., Elias, D. M. O., Ewers, R. M., Milodowski, D. T., et al. (2018). Canopy structure and topography jointly constrain the microclimate of human-modified tropical landscapes. Glob. Change Biol. 24, 5243-5258. doi: $10.1111 / \mathrm{gcb} .14415$

Kearney, M., and Porter, W. (2009). Mechanistic niche modelling: combining physiological and spatial data to predict species' ranges. Ecol. Lett. 12, 334-350. doi: 10.1111/j.1461-0248.2008.01277.x

Keiser, A. D., and Bradford, M. A. (2017). Climate masks decomposer influence in a cross-site litter decomposition study. Soil Biol. Biochem. 107, 180-187. doi: 10.1016/j.soilbio.2016.12.022

Kemp, V. A. (2018). The Effects of Forest Degradation on Trophic Interactions and Elemental Fluxes in an Experimental Landscape, Malaysian Borneo. Queen Mary University of London. Available online at: https://qmro.qmul.ac.uk/ xmlui/bitstream/handle/123456789/56978/Kemp_V_Final_PhD_270219.pdf? sequence $=2$ \&is Allowed $=y$ (accessed August 3, 2019).

Kilpatrick, A. M., and Randolph, S. E. (2012). Drivers, dynamics, and control of emerging vector-borne zoonotic diseases. Lancet 380, 1946-1955. doi: 10.1016/S0140-6736(12)61151-9

Krishna, M. P., and Mohan, M. (2017). Litter decomposition in forest ecosystems: a review. Energy Ecol. Environ. 2, 236-249. doi: 10.1007/s40974-017-0064-9

Lembrechts, J. J., Lenoir, J., Roth, N., Hattab, T., Milbau, A., Haider, S., et al. (2019a). Comparing temperature data sources for use in species distribution models: from in-situ logging to remote sensing. Glob. Ecol. Biogeogr. 28, 1588-1596. doi: 10.1111/geb.12974 
Lembrechts, J. J., Nijs, I., and Lenoir, J. (2019b). Incorporating microclimate into species distribution models. Ecography 42, 1267-1279. doi: 10.1111/ecog.03947

Lenoir, J., Hattab, T., and Pierre, G. (2017). Climatic microrefugia under anthropogenic climate change: implications for species redistribution. Ecography 40, 253-266. doi: 10.1111/ecog.02788

Levy, O., Dayan, T., Porter, W. P., and Kronfeld-Schor, N. (2019). Time and ecological resilience: can diurnal animals compensate for climate change by shifting to nocturnal activity? Ecol. Monogr. 89:e01334. doi: 10.1002/ecm.1334

Lewis, S. L., Edwards, D. P., and Galbraith, D. (2015). Increasing human dominance of tropical forests. Science 349, 827-832. doi: $10.1126 /$ science.aaa9932

Luke, S. H., Slade, E. M., Gray, C. L., Annammala, K. V., Drewer, J., Williamson, J., et al. (2019). Riparian buffers in tropical agriculture: Scientific support, effectiveness and directions for policy. J. Appl. Ecol. 56, 85-92. doi: 10.1111/1365-2664.13280

MacDonald, A. J., and Mordecai, E. A. (2019). Amazon deforestation drives malaria transmission, and malaria burden reduces forest clearing. Proc. Natl. Acad. Sci. U.S.A. 116, 22212-22218. doi: 10.1073/pnas.1905315116

Merow, C., Dahlgren, J. P., Metcalf, C. J. E., Childs, D. Z., Evans, M. E. K. K., Jongejans, E., et al. (2014). Advancing population ecology with integral projection models: a practical guide. Methods Ecol. Evol. 5, 99-110. doi: 10.1111/2041-210X.12146

Milanesi, P., Holderegger, R., Bollmann, K., Gugerli, F., and Zellweger, F. (2017). Three-dimensional habitat structure and landscape genetics: a step forward in estimating functional connectivity. Ecology 98, 393-402. doi: 10.1002/ecy.1645

Mod, H. K., Scherrer, D., Luoto, M., and Guisan, A. (2016). What we use is not what we know: environmental predictors in plant distribution models. J. Veg. Sci. 27, 1308-1322. doi: 10.1111/jvs.12444

Nakamura, A., Kitching, R. L., Cao, M., Creedy, T. J., Fayle, T. M., Freiberg, M., et al. (2017). Forests and their canopies: achievements and horizons in canopy science. Trends Ecol. Evol. 32, 438-451. doi: 10.1016/j.tree.2017. 02.020

Nichols, E., Spector, S., Louzada, J., Larsen, T., Amezquita, S., and Favila, M. E. (2008). Ecological functions and ecosystem services provided by Scarabaeinae dung beetles. Biol. Conserv. 141, 1461-1474. doi: 10.1016/j.biocon.2008.04.011

Novotny, V., Miller, S. E., Baje, L., Balagawi, S., Basset, Y., Cizek, L., et al. (2010). Guild-specific patterns of species richness and host specialization in plantherbivore food webs from a tropical forest. J. Anim. Ecol. 79, 1193-1203. doi: 10.1111/j.1365-2656.2010.01728.x

Ohler, L.-M., Lechleitner, M., and Junker, R. R. (2019). Microclimatic effects on alpine plant and flower visitor communities and their interactions. BioRxiv [Preprint]. doi: 10.1101/646752

Paaijmans, K. P., Heinig, R. L., Seliga, R. A., Blanford, J. I., Blanford, S., Murdock, C. C., et al. (2013). Temperature variation makes ectotherms more sensitive to climate change. Glob. Change Biol. 19, 2373-2380. doi: 10.1111/gcb.12240

Pau, S., Detto, M., Kim, Y., and Still, C. J. (2018). Tropical forest temperature thresholds for gross primary productivity. Ecosphere 9:e02311. doi: $10.1002 /$ ecs 2.2311

Pearce, J. M. (2012). Building research equipment with free, open-source hardware. Science 337, 1303-1304. doi: 10.1126/science. 1228183

Pfeifer, M., Lefebvre, V., Peres, C. A., Banks-Leite, C., Wearn, O. R., Marsh, C. J., et al. (2017). Creation of forest edges has a global impact on forest vertebrates. Nature 551, 187-191. doi: 10.1038/nature24457

Phillips, J. W., Chung, A. Y. C., Edgecombe, G. D., and Ellwood, M. D. F. (2019). Bird's nest ferns promote resource sharing by centipedes. Biotropica. doi: 10.1111/btp.12713. [Epub ahead of print].

Porter, J. H., Nagy, E., Kratz, T. K., Hanson, P., Collins, S. L., and Arzberger, P. (2009). New eyes on the world: advanced sensors for ecology. Bioscience 59, 385-397. doi: 10.1525/bio.2009.59.5.6

Potter, K. A., Arthur Woods, H., and Pincebourde, S. (2013). Microclimatic challenges in global change biology. Glob. Change Biol. 19, 2932-2939. doi: $10.1111 /$ gcb.12257

Putz, F. E., Sist, P., Fredericksen, T., and Dykstra, D. (2008). Reduced-impact logging: challenges and opportunities. For. Ecol. Manage. 256, 1427-1433. doi: 10.1016/j.foreco.2008.03.036

Qie, L., Telford, E. M., Massam, M. R., Tangki, H., Nilus, R., Hector, A., et al. (2019). Drought cuts back regeneration in logged tropical forests. Environ. Res. Lett. 14:045012. doi: 10.1088/1748-9326/ab0783
Raine, E. H., Gray, C. L., Mann, D. J., and Slade, E. M. (2018a). Tropical dung beetle morphological traits predict functional traits and show intraspecific differences across land uses. Ecol. Evol. 8, 8686-8696. doi: 10.1002/ ece3.4218

Raine, E. H., Mikich, S. B., Lewis, O. T., Riordan, P., Vaz-De-Mello, F. Z., and Slade, E. M. (2018b). Extinctions of interactions: quantifying a dung beetle-mammal network. Ecosphere 9:e02491. doi: 10.1002/ecs2.2491

Riutta, T., Clack, H., Crockatt, M., and Slade, E. M. (2016). Landscape-scale implications of the edge effect on soil fauna activity in a temperate forest. Ecosystems 19, 534-544. doi: 10.1007/s10021-015-9939-9

Riutta, T., Malhi, Y., Kho, L. K., Marthews, T. R., Huaraca Huasco, W., Khoo, M., et al. (2018). Logging disturbance shifts net primary productivity and its allocation in Bornean tropical forests. Glob. Change Biol. 24, 2913-2928. doi: $10.1111 / \mathrm{gcb} .14068$

Rivera-Ordonez, J. M., Justin Nowakowski, A., Manansala, A., Thompson, M. E., and Todd, B. D. (2019). Thermal niche variation among individuals of the poison frog, Oophaga pumilio, in forest and converted habitats. Biotropica 51, 747-756. doi: 10.1111/btp.12691

Rodríguez-Ronderos, M. E., Bohrer, G., Sanchez-Azofeifa, A., Powers, J. S., and Schnitzer, S. A. (2016). Contribution of lianas to plant area index and canopy structure in a Panamanian forest. Ecology 97, 3271-3277. doi: 10.1002/ecy.1597

Scheffers, B. R., Edwards, D. P., Diesmos, A., Williams, S. E., and Evans, T. A. (2014). Microhabitats reduce animal's exposure to climate extremes. Glob. Change Biol. 20, 495-503. doi: 10.1111/gcb.12439

Scheffers, B. R., Edwards, D. P., Macdonald, S. L., Senior, R. A., Andriamahohatra, L. R., Roslan, N., et al. (2017). Extreme thermal heterogeneity in structurally complex tropical rain forests. Biotropica 49, 35-44. doi: 10.1111/btp. 12355

Schleuning, M., Fründ, J., Schweiger, O., Welk, E., Albrecht, J., Albrecht, M., et al. (2016). Ecological networks are more sensitive to plant than to animal extinction under climate change. Nat. Commun. 7:13965. doi: 10.1038/ncomms13965

Senior, R. A., Hill, J. K., and Edwards, D. P. (2019). ThermStats: an R package for quantifying surface thermal heterogeneity in assessments of microclimates. Methods Ecol. Evol. 10, 1606-1614. doi: 10.1111/2041-210X.13257

Senior, R. A., Hill, J. K., González del Pliego, P., Goode, L. K., and Edwards, D. P. (2017). A pantropical analysis of the impacts of forest degradation and conversion on local temperature. Ecol. Evol. 7, 7897-7908. doi: $10.1002 /$ ece 3.3262

Silvério, D. V., Brando, P. M., Balch, J. K., Putz, F. E., Nepstad, D. C., Oliveira-Santos, C., et al. (2013). Testing the amazon savannization hypothesis: fire effects on invasion of a neotropical forest by native cerrado and exotic pasture grasses. Philos. Trans. R. Soc. B Biol. Sci. 368:20120427. doi: 10.1098/rstb.2012.0427

Slade, E. M., Bagchi, R., Keller, N., and Philipson, C. D. (2019). When do more species maximize more ecosystem services? Trends Plant Sci. 24, 790-793. doi: 10.1016/j.tplants.2019.06.014

Slade, E. M., Kirwan, L., Bell, T., Philipson, C. D., Lewis, O. T., and Roslin, T. (2017). The importance of species identity and interactions for multifunctionality depends on how ecosystem functions are valued. Ecology 98, 2626-2639. doi: 10.1002/ecy.1954

Slade, E. M., and Roslin, T. (2016). Dung beetle species interactions and multifunctionality are affected by an experimentally warmed climate. Oikos 125, 1607-1616. doi: 10.1111/oik.03207

Smits, W. T. M. (1994). Dipterocarpaceae: Mycorrhizae and Regeneration. Wageningen: Wageningen Agricultural University.

Swab, R. M., Regan, H. M., Matthies, D., Becker, U., and Bruun, H. H. (2015). The role of demography, intra-species variation, and species distribution models in species projections under climate change. Ecography 38, 221-230. doi: 10.1111/ecog. 00585

Swinfield, T., Both, S., Riutta, T., Bongalov, B., Elias, D., Majalap-Lee, N., et al. (2019). Imaging spectroscopy reveals the effects of topography and logging on the leaf chemistry of tropical forest canopy trees. Glob. Chang. Biol. doi: 10.1111/gcb.14903. [Epub ahead of print].

Tuma, J., Fleiss, S., Eggleton, P., Frouz, J., Klimes, P., Lewis, O. T., et al. (2019). Logging of rainforest and conversion to oil palm reduces bioturbator diversity but not levels of bioturbation. Agric. Ecosyst. Environ. Appl. Soil Ecol. 144, 123-133. doi: 10.1016/j.apsoil.2019.07.002 
Tylianakis, J. M., Didham, R. K., Bascompte, J., and Wardle, D. A. (2008). Global change and species interactions in terrestrial ecosystems. Ecol. Lett. 11, 1351-1363. doi: 10.1111/j.1461-0248.2008.01250.x

Walsh, B. S., Parratt, S. R., Hoffmann, A. A., Atkinson, D., Snook, R. R., Bretman, A., et al. (2019). The impact of climate change on fertility. Trends Ecol. Evol. 34, 249-259. doi: 10.1016/j.tree.2018.12.002

Wearn, O. R., Rowcliffe, J. M., Carbone, C., Pfeifer, M., Bernard, H., and Ewers, R. M. (2017). Mammalian species abundance across a gradient of tropical land-use intensity: a hierarchical multi-species modelling approach. Biol. Conserv. 212, 162-171. doi: 10.1016/j.biocon.2017.05.007

Weedon, J. T., Cornwell, W. K., Cornelissen, J. H. C., Zanne, A. E., Wirth, C., and Coomes, D. A. (2009). Global meta-analysis of wood decomposition rates: a role for trait variation among tree species? Ecol. Lett. 12, 45-56. doi: 10.1111/j.1461-0248.2008.01259.x

Wild, J., Kopecký, M., Macek, M., Šanda, M., Jankovec, J., and Haase, T. (2019). Climate at ecologically relevant scales: a new temperature and soil moisture logger for long-term microclimate measurement. Agric. For. Meteorol. 268, 40-47. doi: 10.1016/j.agrformet.2018.12.018

Will, R. E., Wilson, S. M., Zou, C. B., and Hennessey, T. C. (2013). Increased vapor pressure deficit due to higher temperature leads to greater transpiration and faster mortality during drought for tree seedlings common to the forest-grassland ecotone. New Phytol. 200, 366-374. doi: 10.1111/nph. 12321

Woon, J. S., Boyle, M. J. W., Ewers, R. M., Chung, A., and Eggleton, P. (2019). Termite environmental tolerances are more linked to desiccation than temperature in modified tropical forests. Insect. Soc. 66, 57-64. doi: 10.1007/s00040-018-0664-1
World Health Organisation. (2017). Global Vector Control Response 2017-2030. Geneva: World Health Organization Available online at: https://www.who. int/vector-control/publications/global-control-response/en/ (accessed August 7, 2019).

Zellweger, F., Baltensweiler, A., Schleppi, P., Huber, M., Küchler, M., Ginzler, C., et al. (2019a). Estimating below-canopy light regimes using airborne laser scanning: an application to plant community analysis. Ecol. Evol. 9, 1-11. doi: $10.1002 /$ ece 3.5462

Zellweger, F., Frenne, P., De, Lenoir, J., Rocchini, D., and Coomes, D. (2019b). Advances in microclimate ecology arising from remote sensing. Trends Ecol. Evol. 34, 327-341. doi: 10.1016/j.tree.2018.12.012

Zurell, D., Thuiller, W., Pagel, J., Cabral, J. S., Münkemüller, T., Gravel, D., et al. (2016). Benchmarking novel approaches for modelling species range dynamics. Glob. Change Biol. 22, 2651-2664. doi: 10.1111/gcb.13251

Conflict of Interest: The authors declare that the research was conducted in the absence of any commercial or financial relationships that could be construed as a potential conflict of interest.

Copyright (C) 2020 Jucker, Jackson, Zellweger, Swinfield, Gregory, Williamson, Slade, Phillips, Bittencourt, Blonder, Boyle, Ellwood, Hemprich-Bennett, Lewis, Matula, Senior, Shenkin, Svátek and Coomes. This is an open-access article distributed under the terms of the Creative Commons Attribution License (CC BY). The use, distribution or reproduction in other forums is permitted, provided the original author(s) and the copyright owner(s) are credited and that the original publication in this journal is cited, in accordance with accepted academic practice. No use, distribution or reproduction is permitted which does not comply with these terms. 